\title{
The impact of social distancing on box-office revenue: Evidence from the COVID-19 pandemic
}

\author{
In Kyung Kim ${ }^{1}$
}

Received: 26 April 2020 / Accepted: 29 September 2020 / Published online: 21 October 2020

(C) Springer Science+Business Media, LLC, part of Springer Nature 2020

\begin{abstract}
In this paper, I study the short-run effect of social distancing due to the COVID-19 outbreak on movie demand and box-office revenue. Using longitudinal data on the Korean movie theater industry, I first estimate a nested logit model of movie demand, and then quantify the revenue loss in the industry. Estimation results reveal that the revenue loss due to the decrease in underlying movie demand is approximately 52 million dollars nationwide during the first five weeks after the outbreak, implying a 34 percent decrease in sales. The results also suggest an additional 42 million dollars were lost as the delay of some major movies lowered the overall quality of available movies in the market.
\end{abstract}

Keywords COVID-19 - Social distancing · Movie theater industry ·

Nested logit model

JEL Classification $\mathrm{L} 1 \cdot \mathrm{L} 8 \cdot \mathrm{M} 2$

\section{Introduction}

2019 novel coronavirus disease (COVID-19) has caused an unprecedented health crisis. It was designated a pandemic by the World Health Organization (WHO) on 11 March 2020, and one month later the worldwide number of confirmed cases reached 1.7 million, with 100,000 deaths. The outbreak of COVID-19 also hit the economy severely, not only causing higher unemployment rates and lower income but also causing people to practice social distancing, that is, avoiding close contact with other people, which may have far-ranging implications for various industries. As the

In Kyung Kim

in.kim@nu.edu.kz

1 Department of Economics, Nazarbayev University, Astana, 010000, Kazakhstan 
COVID-19 pandemic is expected to last at least till next year ${ }^{1}$ and more pandemics are expected to come in the near future (Frutos et al. 2020), voluntary social distancing has been gradually accepted as the new normal around the world. For instance, recent research has shown that voluntary demobilisation is crucial for reducing virus propagation (Maloney and Taskin 2020; Gupta et al. 2020). ${ }^{2}$

The goal of this paper is to study the short-run impact of social distancing due to the COVID-19 outbreak on the Korean movie theater industry. The first confirmed case of the novel coronavirus infection in Korea on 20 January 2020 caused widespread fear of going to the cinema among Koreans. Although the Korean government urged people to minimize social contact as much as possible, it did not impose any restriction on commercial or religious activities and public gatherings at least until mid March. ${ }^{3}$ Consequently, any decrease in a retailer's revenue during the first few weeks after the COVID-19 outbreak would be attributed to consumers' voluntary social distancing practices rather than government-imposed restrictions.

As the plunge in underlying movie demand resulted in a sharp drop in ticket sales, distributors delayed some of their potentially popular movies, which in turn might have led to a further decrease in box-office revenue. A novel contribution of this paper is to distinguish between the revenue loss caused by reduced movie demand after the outbreak and the loss attributed to the endogenous market reaction. This is important in that a firm's managerial decision on the distribution channel (for example, online vs offline), $R \& D$ expenditure, product line, and prices would be based on the extent to which consumer demand is affected by such an exogenous disturbance. Although a specific sector (movie theater industry) is analyzed in this paper, the empirical strategy proposed in this article can be applied to other industries, such as automotive or electronics manufacturing, in other countries where the pandemic delayed new product launches. $^{4}$

I focus on the changes in the first few weeks after the outbreak for various reasons. First, the effect of social distancing is unlikely to be the same before and after the last week of February, when the number of confirmed cases began to surge in Korea, possibly causing people to intensify social distancing. Second, some theaters were shutdown starting from late March, which might have further lowered movie demand. Third, since schools and universities in Korea normally start in March, there would be confounding changes in underlying movie demand due to the postponement of the start of a new school year if observations of March and later are included.

Using multi-market data from the first week of January 2017 to the third week of February 2020, I first estimate a nested logit model of movie demand similar to those considered in the previous literature (Einav 2007; Moul 2007; Leung et al. 2019).

\footnotetext{
${ }^{1}$ https://www.nytimes.com/2020/05/08/health/coronavirus-pandemic-curve-scenarios.html

${ }^{2}$ As for the determinants of individual mobility during the COVID-19 pandemic, mobility declines more in regions with high-speed internet (Chiou and Tucker 2020) or with higher civic capital (Durante et al. 2020).

${ }^{3}$ https://www.economist.com/business/2020/03/26/how-retailers-vie-to-be-considered-essential-in-alockdown

${ }^{4}$ The following news articles report product launch delays in the above industries. https://www. thedetroitbureau.com/2020/06/automakers-continue-to-delay-product-launches-in-wake-of-pandemic/ https://www.eetimes.com/pandemic-delays-electronic-product-launches/
} 
Estimation results reveal that while in all markets the COVID-19 outbreak had a strong negative effect on a consumer's utility from watching her favorite movie, its magnitude is largest in densely populated metropolitan areas. This finding suggests that people in these regions practiced social distancing more carefully than people in other regions with lower population density. I also find evidence that people are more afraid of going to the cinema when they are more concerned about the pandemic or there is more news about the novel virus.

Next, I examine what box office revenue would have been in each market and nationwide during the first five weeks since the outbreak of COVID-19 had it not broken out. Using the estimated demand parameters, I derive the counterfactual boxoffice revenue in a market and compare it with the observed revenue to obtain the estimated short-run revenue loss in the market. I find that the market-level revenue loss ranges from 400 thousand dollars to 16 million dollars. The estimated loss is 52 million dollars nationwide while the box-offce revenue during this period is 102 million dollars, implying a 34 percent decrease in sales in the short-run. The estimated revenue loss, 52 million dollars, is much smaller than the difference between sales during these five weeks in 2020 and sales during the same period in the previous year, 94 million dollars. This gap can be largely attributed to endogenous movie quality choice by distributors. That is, as people were reluctant to go to the cinema, major distributors delayed some of their potentially popular movies, lowering the overall quality of available movies in the market.

This paper contributes to the literature that combines epidemiology and economics. ${ }^{5}$ Earlier works on the economic analysis of infectious disease found that the benefit from public intervention is often lower than that predicted by epidemiology (Philipson 2000) or not cost-effective (Adda 2016). Since the outbreak of COVID-19, a growing number of papers study macroeconomic implications of pandemic. These papers consider models where economic factors interact with the virus transmission mechanism, analyzing the efficiency of fiscal and monetary policies (Guerrieri et al. 2020; Faria-e Castro and et al. 2020) or deriving the optimal mitigation policies (Eichenbaum et al. 2020; Alvarez et al. 2020; Jones and Venkateswaran 2020). This paper is one of the first empirical studies on the effect of the epidemic on a certain industry. A group of papers studied how the tourism industry was affected by epidemics such as avian flu and SARS during the 2000s (Kuo et al. 2009; Chen et al. 2007). While they relied on reduced-form models for their analyses, I consider a discrete-choice model and quantify the revenue loss in the industry due to the outbreak of COVID-19.

Recent literature on movie demand estimation also bears on this paper. (Einav 2007) estimated a nested logit model where all movies are grouped into one set and the outside option composes another set. He distinguished between seasonality in unobserved movie demand and the endogenous market response to it, that is, the choice of quality and number of movies, and found that the latter explains one third

\footnotetext{
${ }^{5}$ Papers that studied the impact of a pandemic at the macro level before the outbreak of COVID-19 include (Keogh-Brown et al. 2010) (on economic growth), Boucekkine and Laffargue (2010) (on income distribution), and Chakraborty et al. (2010) (on economic development). See Perrings et al. (2014) for a literature review.
} 
of the seasonal variation in box-office revenue in the U.S. market. Moul (2007) proposed an error components approach and found strong evidence of word of mouth effect in the U.S. market, that is, information transmission explains about 10 percent of the variance in consumer expectations of movies in the market. Leung et al. (2019) took the movie availability in theaters into account when estimating the movie demand model, and showed that it is an important determinant of box-office revenue in the U.S. market. Following these works, in this paper I consider the nested logit framework for movie demand estimation, but unlike them, I use multi-market data that allow me to estimate the varying effect of the COVID-19 outbreak on consumer utility and ticket sales in different markets.

The remainder of the paper proceeds as follows. I provide background information on the COVID-19 outbreak and the movie theater industry in Korea in the next section, and describe the data in Section 3. Then, I estimate the movie demand model and quantify the box-office revenue loss in Section 4. I carry out a number of robustness checks in Section 5 and conclude in Section 6.

\section{Background information}

\subsection{Outbreak of COVID-19}

On 30 December 2019, Chinese health authorities reported that they were monitoring 27 cases of unexplained viral pneumonia in the city of Wuhan in Hubei province. In early January the following year, Chinese researchers identified a novel coronavirus as the pathogen causing a cluster of the pneumonia cases. By late January, the virus had spread not only to other provinces in China, but also to its neighboring countries such as Japan, Singapore, and South Korea. On 11 February WHO named the syndrome associated with novel coronavirus COVID-19, which kept spreading all over the world. WHO declared it a global pandemic on March 11, when nearly 120,000 people had been infected by the virus and 4,000 lives had been lost because of the COVID-19 viral disease worldwide.

Facing the novel coronavirus outbreak in Wuhan, Korea screened arrivals on flights from the city starting from mid January. On 19 January a Chinese citizen from Wuhan was detected with fever upon arrival at the Incheon International Airport, the largest airport in Korea, and was confirmed on the next day as the first case of novel coronavirus infection in Korea. Four days later a man from Wuhan was confirmed positive for the new coronavirus, the first infection case of a Korean citizen. The left panel of Fig. 1 shows that in Korea the number of confirmed cases of COVID-19 has soared since late February, surging to almost 10 thousand by the end of March. Also, according to the figure the cases mostly came from Daegu, the fourth largest city in Korea, led by two clusters of infections: a religious organization, Shincheonji, and a hospital in Cheongdo, a neighboring county. On March 15, Daegu city and several parts of Kyungbook province including Cheongdo were designated as special disaster zones, receiving special medical and financial support from the central government.

The earlier cases of infection in late January caused widespread fear among Koreans, as some family members, friends, and acquaintances of those infected also 
(a) Number of confirmed cases

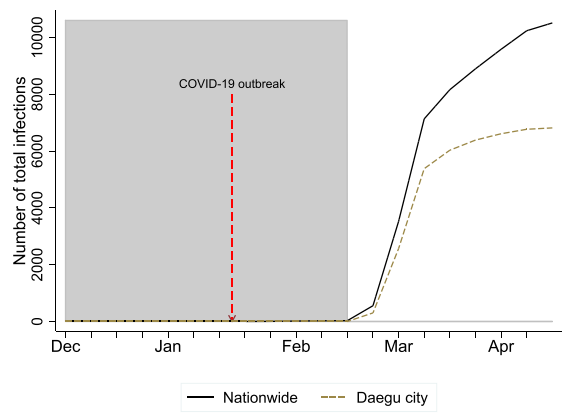

(b) Google search trend

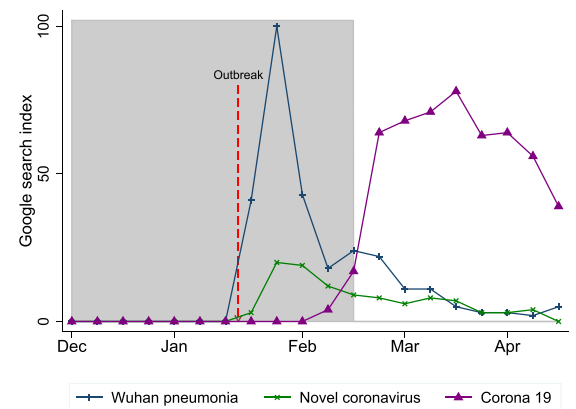

Fig. 1 Outbreak of COVID-19 in Korea Shaded area covers weeks included in the sample period. Source: Korea Centers for Disease Control and Prevention (KCDC) and Google Trends

contracted the virus. Places they visited before confirmation of their illness were disinfected, while search volume for three terms related to the virus -'Wuhan pneumonia', 'novel coronavirus', 'Corona 19'- peaked during the fifth week of January, one week after the first confirmed case (see the right panel of Fig. 1). ${ }^{6}$

Although the Korean government urged people to minimize social contact as much as possible, it did not impose any restriction on commercial or religious activities and public gatherings. As a result, malls, restaurants, bars, and movie theaters were open as usual at least until mid March. Consequently, any decrease in a retailer's revenue during the first few weeks after the COVID-19 outbreak would be attributed to consumers' voluntary social distancing practices rather than government-imposed restrictions.

\subsection{Movie theater industry}

After a period of strong expansion between the late 1990s and early 2010s, the movie theater industry in Korea became mature and stabilized. ${ }^{7}$ According to the top left panel of Fig. 2, the nationwide audience size increased from 150 million in 2010 to 210 million in 2013, thanks to the success of local movies. Since then, however, there has been hardly any change in yearly consumer demand. Therefore, in the empirical analysis in Section 4, I assume that expected sales in 2020 would be the same as sales in the previous year to distinguish between the revenue loss due to reduced movie demand and the loss due to the endogenous movie quality choice by distributors.

In 2018, Korea was the fifth largest movie theater market in the world in terms of box office revenue (US\$ 1.6 billion). ${ }^{8}$ Unlike the U.S., vertical integration between distributors and exhibitors is allowed in Korea. Table 4 in the Appendix shows that

\footnotetext{
${ }^{6}$ Koreans called the novel coronavirus 'Wuhan pneumonia' until WHO named it COVID-19 on 11 February. It is now typically referred to as Corona 19 in Korea.

${ }^{7} \mathrm{Kim}(2019,2020)$ provide a detailed description of the Korean movie theater industry during the 2000s and the early 2010 s.

${ }^{8}$ https://www.motionpictures.org/wp-content/uploads/2019/03/MPAA-THEME-Report-2018.pdf
} 
(a) Yearly audience size: 2010-2019

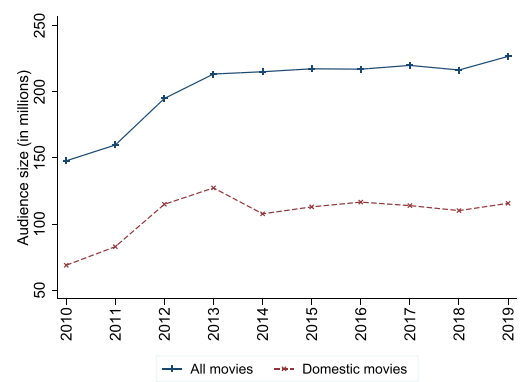

(b) Weekly audience size: 2019-2020

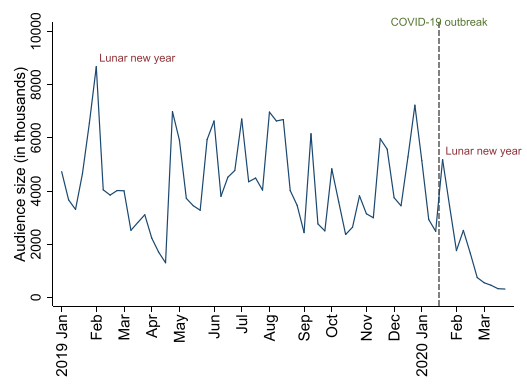

(c) Monthly ticket price: 2019-2020

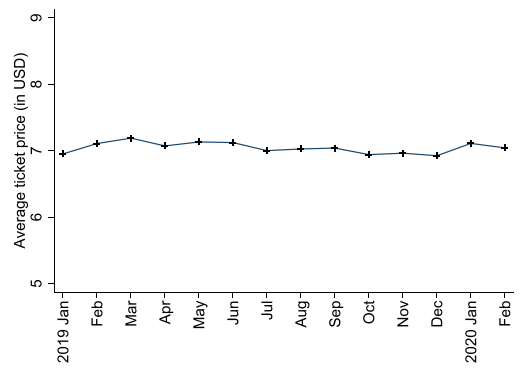

Fig. 2 Trends in movie demand and price Source: Korean Film Council Annual Reports and KOBIS

as a result, there are three corporations, CJ, Lotte, and JContentree, whose combined market share was over 90 percent in the exhibition industry $(2,835$ out of 3,079 screens) and 30 percent in the distribution industry (71 out of 227 million consumers) in 2019.

Growing anxiety about the COVID-19 epidemic led people to practice social distancing, which in turn had a strong negative effect on movie demand. The top right panel of Fig. 2 demonstrates that 40 percent fewer people went to the cinema during the Lunar New Year in 2020 than in 2019. Also, according to the figure the nationwide audience size fluctuates over the course of a year, reflecting both seasonality in underlying movie demand and seasonality in movie quality and number (Einav 2007). After the Lunar New Year holiday, for instance, the audience size shows the same declining pattern during February and March in both years.

As the COVID-19 epidemic was prolonged, Time to Hunt, a local movie whose theatrical release was initially scheduled for 26 February but was postponed twice, was released on 23 April by Netflix. With a production cost of 10 billion Korean won (approximately 8.3 million US dollars), the movie was expected to enjoy success at the box office. ${ }^{9}$ While this is the only case of skipping the theatrical release in Korea so far, delay of movies was more common. For example, the number of

\footnotetext{
${ }^{9}$ Among 339 local movies released in 2019, only 10 movies had a production cost equal to or higher than Time to Hunt. 
delayed movies reached 50 by early March. ${ }^{10}$ Also, chains started to close some theaters starting in late March as movie demand plunged; CJ suspended operation of 35 theaters in late March, while JContentree decided to shut down 10 theaters in April. ${ }^{11}$

The movie theater industry is characterized by its uniform pricing practice, that is, all shows in a theater during a given time slot tend to be equally priced. ${ }^{12}$ Interestingly, movie theaters did not lower the admission price after the COVID-19 outbreak despite the sharp decline in their sales records. The bottom panel of Fig. 2, for instance, shows that the average admission price (box-office revenue divided by audience size) was around 7 dollars during 2019, and there is no clear evidence that the price decreased in January and February. Given the uniformity and rigidity of the price, similar to previous studies on movie demand estimation (Einav 2007; Moul 2008; Leung et al. 2019) I assume that the price is exogenously determined and fixed in the empirical analysis.

\section{Data}

Korea is composed of 17 major administrative divisions: seven metropolitan cities, nine provinces, and one special autonomous city, Sejong, which was founded in 2012 as Korea's new capital city. Since construction of Sejong city is still underway, I drop it from the analysis and define each of the remaining 16 administrative divisions as a market. I download movie-market-week level demand information - audience size as well as box-office revenue - between January 2017 and February 2020 from the Korea Box-office Information System (KOBIS). ${ }^{13}$ The left panel of Fig. 1 demonstrates that the number of confirmed cases surged from the last week of February. Therefore, I restrict the sample period up to the third week of February; the effect of social distancing incurred by the outbreak of COVID-19 is unlikely to be the same afterwards. Moreover, since Korea normally starts schools and universities in March, there would be confounding changes in underlying movie demand due to the delay of the start of a new school year if observations of March and later months of 2020 are included.

Figure 3 presents the timeline of major events regarding COVID-19 in Korea. According to the figure, the first shutdown of a movie theater (CGV Sungsin) took place on the last day of January. After cleaning and disinfection, the theater reopened three days later on 3 February. There are four more cases of temporary closure during the sample period. ${ }^{14}$ Since the demand information is aggregated at the market level,

\footnotetext{
${ }^{10}$ https://m.newspim.com/news/view/20200306000789

${ }^{11}$ http://www.koreaherald.com/view.php?ud=20200326000210

${ }^{12}$ Orbach and Einav (2007) pointed out demand uncertainty, monitoring costs, and perceived fairness, as possible explanations for this practice, while Courty and Nasiry (2018) showed that the puzzle may be attributed to consumer loss aversion.

${ }^{13} \mathrm{http} / / /$ www.kobis.or.kr/kobis/business/main/main.do. The data and code for the key empirical findings of the paper are available at GitHub (https://github.com/kimik0121/COVID-19).

${ }^{14}$ They are (i) CGV Bucheon station (1-3 Feb), (ii) CGV Daegu-Hyundai (21-22 Feb), (iii) CGV JeonjuHyoja (21-23 Feb), and (iv) Lotte Jeonju (21-23 Feb). Unlike these temporary shutdowns, chains closed some theaters starting in late March, as described in the previous section.
} 


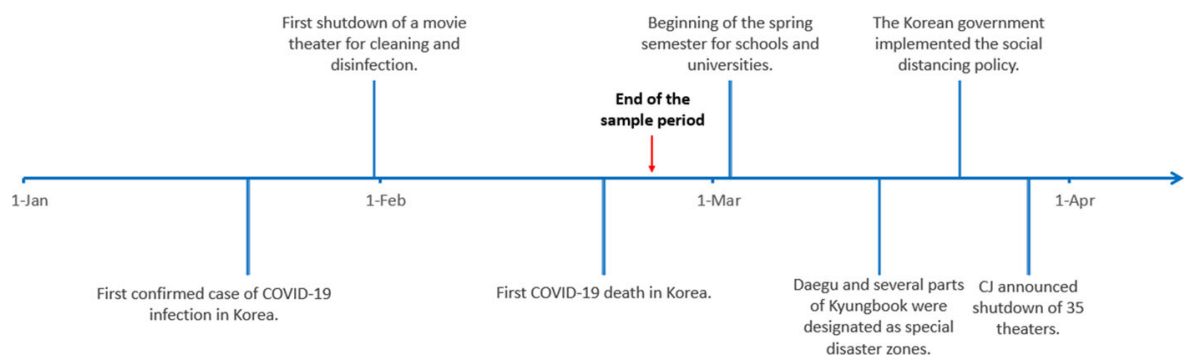

Fig. 3 Timeline of major events

these theaters and the demand for them cannot be taken away. However, given that the shutdown lasted only for 2-3 days and there are merely five such temporary closures during the sample period, they are unlikely to cause any serious bias in the estimation.

I exclude movies without release date information, movies that were played in less than 50 screens nationwide at all weeks during their run, and observations with zero audience size. ${ }^{15}$ I also drop observations of a movie in any given week if the movie is played only in one market in that week. In the following section, I explain that instrumental variables can not be constructed for such cases. After excluding them, I have a sample of 78,635 movie-market-week level observations with 1,136 movie titles.

I define market size as the number of Koreans between age 10 and 80 years within an administrative district, assuming that each of them goes to the cinema once a week at maximum. I download the population data for the year 2018 from the Korean Statistical Information Service. ${ }^{16}$ Table 5 in the Appendix shows that market size ranges from 560 thousand people (Jeju province) to 11 million (Kyungki province). For each market and week, I obtain the market share of a movie by dividing its audience size by the market size, and also create two binary variables: COVID -19 and Holiday. The former is equal to one if the data point occurs after the third week of January 2020, while the latter is equal to one if either Lunar New Year or Chuseok (the Korean Thanksgiving Day) is included in the week. Both are based on the lunar calendar and are the two largest holidays in Korea.

The descriptive statistics presented in Table 1 show that on average a movie attracts approximately 8,500 people in a market in a given week. Equivalently, the average market share is 0.3 percent. The median audience size is merely 270 , and thus, the distribution of audience size is right-skewed. The movie with the maximum market-week level audience size, 1.6 million, is Avengers: Endgame which was released in the last week of April 2019. 3 percent of observations cover periods after the COVID-19 outbreak, while 4 percent of observations are from weeks including one of the two largest holidays, Lunar New Year and Chuseok.

\footnotetext{
${ }^{15}$ Later, I check the robustness of the empirical findings by changing the threshold screen count to 30 and 70 .

${ }^{16}$ At the time of writing yearly population data were not yet available for years 2019 and 2020 . Therefore, I did not compute weekly populations by linear interpolation.
} 
Table 1 Descriptive statistics

\begin{tabular}{llllll}
\hline Variables & Mean & Median & Std. Dev. & Min. & Max. \\
\hline Audience size & 8,528 & 273 & 41,598 & 1 & $1,622,640$ \\
Demand share of a movie (\%) & 0.29 & 0.01 & 0.93 & 0.00 & 18.21 \\
Weeks passed after the release & 3.61 & 2 & 8.43 & 0 & 163 \\
COVID-19 & 0.03 & 0 & 0.17 & 0 & 1 \\
Holiday & 0.04 & 0 & 0.20 & 0 & 1 \\
\hline
\end{tabular}

Table 6 in the Appendix compares sales during the first five weeks after the COVID-19 outbreak in 2020 (4th-8th week of the year) and the sales during the same period in the previous year. The table shows that the nationwide box-office revenue was 196 million dollars in 2019, but decreased 50 percent to 102 million dollars in 2020. While this decline could be attributed to reduced underlying movie demand, the lower movie quality due to the delay of potentially popular movies could also have caused the sales drop. In the next section, I distinguish between the two effects.

\section{Empirical analysis}

I start this section with the movie demand estimation. While the demand estimation itself is interesting and important, the main goal of this paper is to quantify the revenue loss in the industry due to the outbreak of COVID-19. Therefore, I consider a structural model rather than a reduced-form model; I first estimate the discrete-choice model, and then, using the estimated demand parameters, I conduct counterfactual analyses and examine what box office revenue would be had the outbreak not occurred. $^{17}$

\subsection{Movie demand}

Following previous literature on movie demand estimation (Einav 2007; Moul 2007; Leung et al. 2019), I adopt the nested logit framework where all movies are nested into one group. Specifically, I define consumer $i$ 's utility from watching movie $j$ in market $m$ at time (year-week) $t, u_{i j m t}$, and the utility from the outside option, $u_{i 0 m t}$, in the following way:

$$
\begin{aligned}
u_{i j m t} & =\delta_{j m t}+v_{i m t}+(1-\sigma) \varepsilon_{i j m t} \\
& =\alpha_{j}+\beta r_{j t}+\mathbf{x}_{m t} \gamma+\xi_{j m t}+v_{i m t}+(1-\sigma) \varepsilon_{i j m t}, \\
u_{i 0 m t} & =v_{i m t}^{\prime}+(1-\sigma) \varepsilon_{i 0 m t} .
\end{aligned}
$$

\footnotetext{
${ }^{17}$ In addition, estimation of the reduced-form model is not simpler than estimating the nested logit model considered here. Consider a reduced-form model where the audience size of a movie or its revenue is the dependent variable. Since the revenue depends on the release-timing of other movies, control variables such as the number of movies or a measure of rival movies' quality should be included in the model. This requires instrumental variables as well as a proxy variable for the movie quality.
} 
where the mean utility of movie $j, \delta_{j m t}$, depends on movie specific effect $\alpha_{j}$, the number of weeks since release $r_{j t},{ }^{18}$ a vector of market demand shifters $\mathbf{x}_{m t}$, and the movie-market-week specific variation in utility $\xi_{j m t}$, which is assumed to be uncorrelated across markets.

$v_{i m t}+(1-\sigma) \varepsilon_{i j m t}$ is the idiosyncratic taste shock where $v_{i m t}$ is common to all movies for consumer $i$ and its distribution depends on the parameter $\sigma \in[0,1]$. Assuming that $\varepsilon_{i j m t}$ is an i.i.d extreme value random variable, $v_{i m t}+(1-\sigma) \varepsilon_{i j m t}$ is also extreme value distributed (Cardell 1997; Berry 1994). Under this specification, $\sigma$ captures the substitution between going to the cinema and the outside option of not watching any movie (Einav 2007).

The industry market share, that is, the nested logit probability of going to the cinema, is

$$
s_{m t}=\frac{D_{m t}^{1-\sigma}}{1+D_{m t}^{1-\sigma}}
$$

where $D_{m t} \equiv \sum_{f=1}^{\mathcal{F}_{m t}} \exp \left(\delta_{f m t} /(1-\sigma)\right)$ and $\mathcal{F}_{m t}$ is the set of available movies. Note that $s_{m t}$ increases as $\sigma$ decreases. Hence, when $\sigma$ is small, the market expansion effect dominates the business stealing effect. ${ }^{19}$ In contrast, when $\sigma$ is close to one, movies are competing for a given number of movie goers. The predicted market share of movie $j$ and the market share of the outside option is

$$
s_{j m t}=\frac{\exp \left(\delta_{j m t} /(1-\sigma)\right)}{D_{m t}^{\sigma}\left(1+D_{m t}^{1-\sigma}\right)} \text { and } s_{0 m t}=\frac{1}{1+D_{m t}^{1-\sigma}} .
$$

From Eqs. 2 and 3, I obtain a linear regression model:

$$
\ln s_{j m t}-\ln s_{0 m t}=\alpha_{j}+\beta r_{j t}+\mathbf{x}_{m t} \gamma+\sigma\left(\ln s_{j m t}-\ln \sum_{f=1}^{\mathcal{F}_{m t}} s_{f m t}\right)+\xi_{j m t} .
$$

The vector $\mathbf{x}_{m t}$ includes the two binary variables that are described in the previous section, COVID - 19 and Holiday, as well as market and week fixed effects that control for unobserved market conditions and seasonality in the underlying movie demand, respectively. Given that the degree of social distancing may differ across markets, I interact $C O V I D-19$ with market dummies. ${ }^{20}$ Note that since the two holidays - Lunar New Year and Chuseok - are celebrated in different calendar weeks each year, the effect of these holidays can be identified separately from week fixed effects. For instance, the Lunar New Year holiday was in the sixth week of 2019, whereas it was in the fifth week of 2020.

\footnotetext{
${ }^{18}$ Hence, $r_{j t}$ is equal to zero for the release week, one for the second week and so on.

${ }^{19}$ When $\sigma$ is equal to zero, model (1) becomes a multinomial logit model where the net market expansion effect is at its maximum.

${ }^{20}$ Choongbook, a province in Korea, is the omitted market.
} 


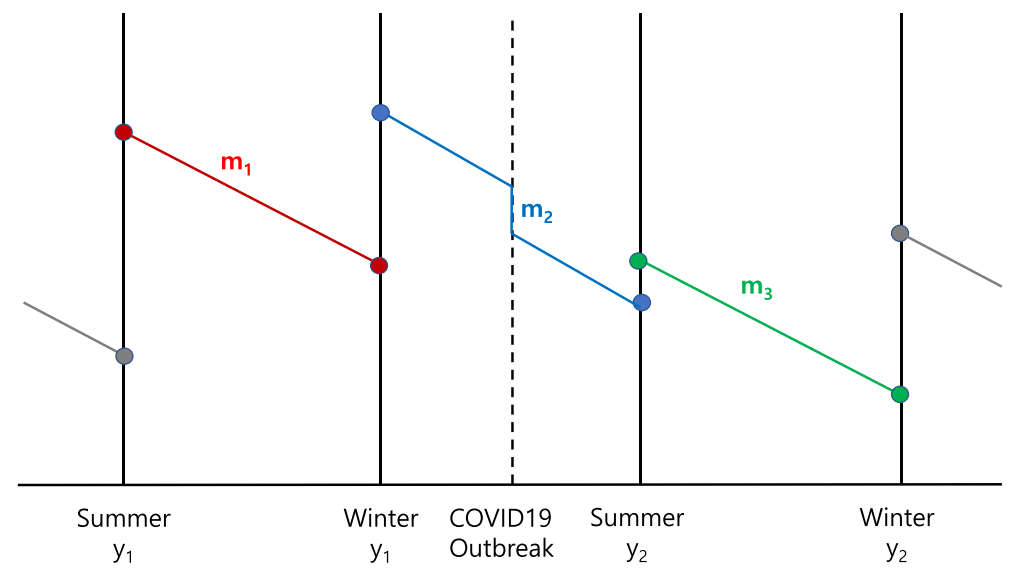

Fig. 4 Identification example

\subsection{Identification}

The identification of movie fixed effects (movie quality) and the COVID-19 effect hinges on the presence of movies that were released before the COVID-19 outbreak and played during the pandemic. As an illustration, suppose that there are two years, $y_{1}$ and $y_{2}$, each of which is composed of two seasons: summer and winter. Due to the seasonality in movie demand, the market size is one in the summer and $M>1$ in the winter. Starting from the summer of $y_{1}$, three movies $\left(m_{1}\right.$ with quality $\theta_{1}$ (normalized to one), $m_{2}$ with quality $\theta_{2}$, and $m_{3}$ with quality $\theta_{3}$ ) are released one after another and played for two seasons. That is, $m_{2}$ is released in the winter of $y_{1}$ and played till summer next year, while $m_{3}$ is played for the two seasons of $y_{2}$, as can be seen in Fig. 4 .

Suppose a movie's demand is equal to its quality times the market size in the release season, and is equal to the quality times the market size times the decay rate $\lambda<1$ in the second season. ${ }^{21}$ A pandemic that occurs in between the two years reduces the market size in each season of $y_{2}$ by $\delta<1$. Under these assumptions, the demand for each movie in each season can be calculated as in the table below:

\begin{tabular}{lll}
\hline & \multicolumn{2}{l}{ Season } \\
\cline { 2 - 3 } Movie & Summer & Winter \\
\hline$m_{1}$ & 1 & $\lambda M$ \\
$m_{2}$ & $\lambda \theta_{2}(1-\delta)$ & $\theta_{2} M$ \\
$m_{3}$ & $\theta_{3}(1-\delta)$ & $\lambda \theta_{3}(M-\delta)$ \\
\hline
\end{tabular}

There are five equations in five unknowns: two movie fixed effects $\left(\theta_{2}, \theta_{3}\right)$, market size $M$, decay rate $\lambda$, and the pandemic effect $\delta$. Consequently, all parameters can be

\footnotetext{
${ }^{21}$ An implicit assumption here is that a movie's demand is independent of those of competing movies.
} 
identified. Note that if movie $m_{2}$ is not released in the winter of $y_{1}$, but in the summer of $y_{2}$ along with $m_{3}$, then the pandemic effect $\delta$ cannot be identified separately from the two movie fixed effects, $\theta_{2}$ and $\theta_{3}$. Put differently, the presence of at least one movie played in both the pre-pandemic and pandemic periods $-m_{2}$ in this example - is crucial for the identification of the pandemic effect, which in turn enables us to identify the quality of movies released after the outbreak.

The sample data analyzed in this paper include 42 movies that were played both before and after the COVID-19 outbreak. The pandemic effect is identified by exploiting the excess drop in demand for each of these movies after the outbreak. Consequently, the pandemic effect and the quality of the 25 movies released after the outbreak (4th-8th week of 2020) can be estimated separately.

Estimation of model (4) requires an instrumental variable since the log of the within-industry market share is endogenous. Similar to Hausman (1996) and Nevo (2001), I use the average log of the within-industry market share of the movie in other markets at the same time as the instrumental variable. If a movie is popular in a market, then it is also likely to be popular in other markets. Also, the instrumental variable is unlikely to be correlated with $\xi_{j m t}$ under the assumption that $\xi_{j m t}$ is uncorrelated across markets. Conversation with two industry experts, both of whom worked for the planning department at CGV, the leading theater chain in Korea, revealed that a movie usually has previews 1-2 weeks before its official release. ${ }^{22}$ Moreover, through social networking services such as Facebook and Twitter people quickly share and gain information on a movie's quality before its release. If this is the case, then any word-of-mouth that affects consumers in all markets would be captured mostly by movie specific effect $\alpha_{j}$, while error term $\xi_{j m t}$ would mainly capture any random movie-market-time specific deviation. ${ }^{23}$

\subsection{Estimation results}

OLS and 2SLS estimation results are presented in Table 2. In all estimations, I report robust standard errors clustered by movie in each market. ${ }^{24}$ They show that while the outbreak of COVID-19 had a negative impact on a consumer's utility from watching a movie in all markets, its magnitude tends to be larger in densely populated markets. More specifically, the sign of the interaction term coefficient is negative for five out of seven metropolitan cities, meaning that the negative effect of COVID-19 was larger in these markets relative to Choongbook province, the omitted market. The two cities, Ulsan and Daejeon, for which the negative COVID-19 effect is smaller compared to the omitted market, have smaller population size with lower population density than other metropolitan cities, as Table 5 in the Appendix shows. In contrast,

\footnotetext{
${ }^{22} 87$ percent of the 1,136 movies analyzed in this paper had preview screenings.

${ }^{23}$ In Section 5, I address the concern that this identifying assumption may be violated.

${ }^{24} \mathrm{As}$ an alternative, I clustered the standard errors at the movie level and confirmed that estimates are not qualitatively different.
} 


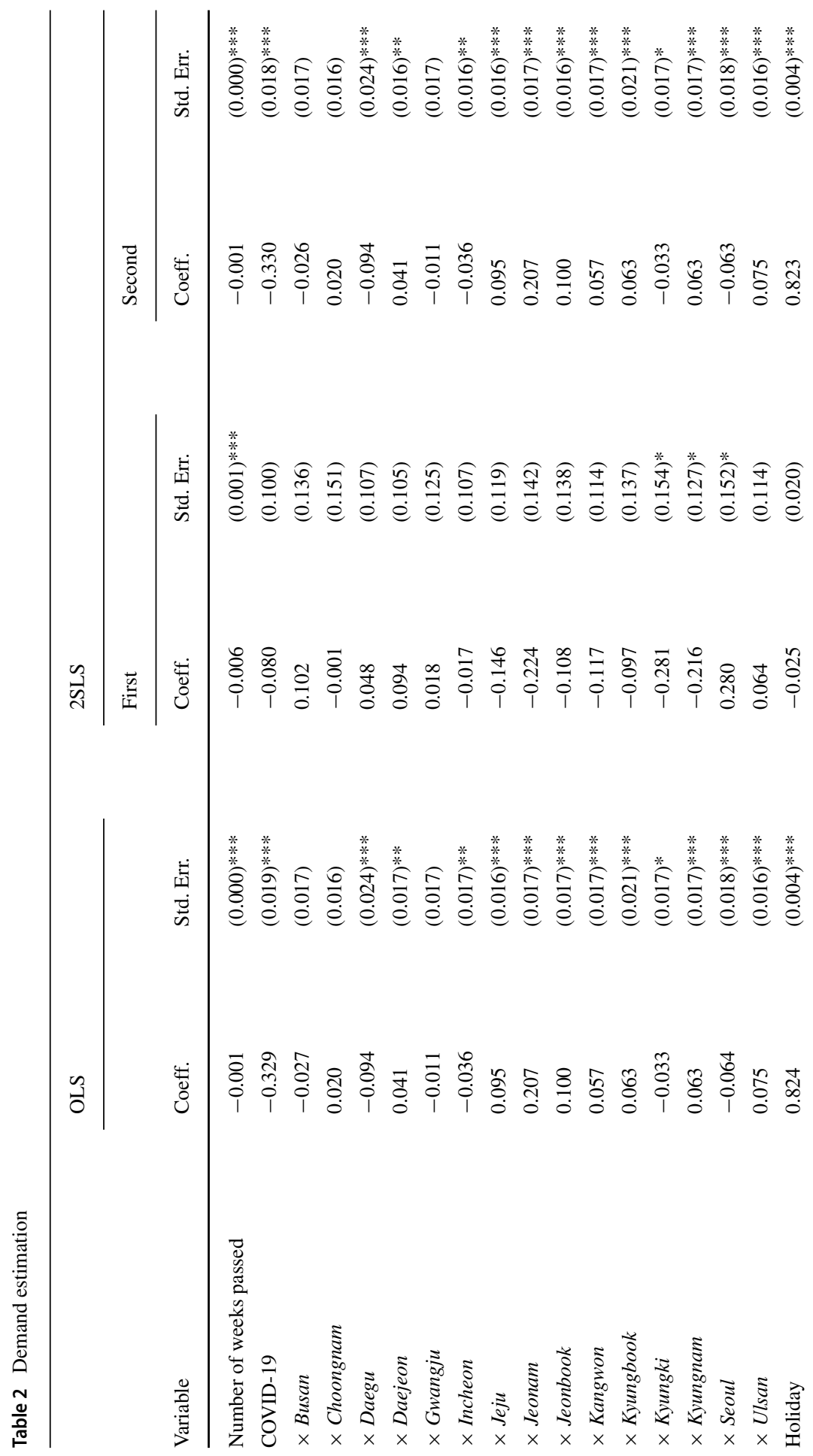




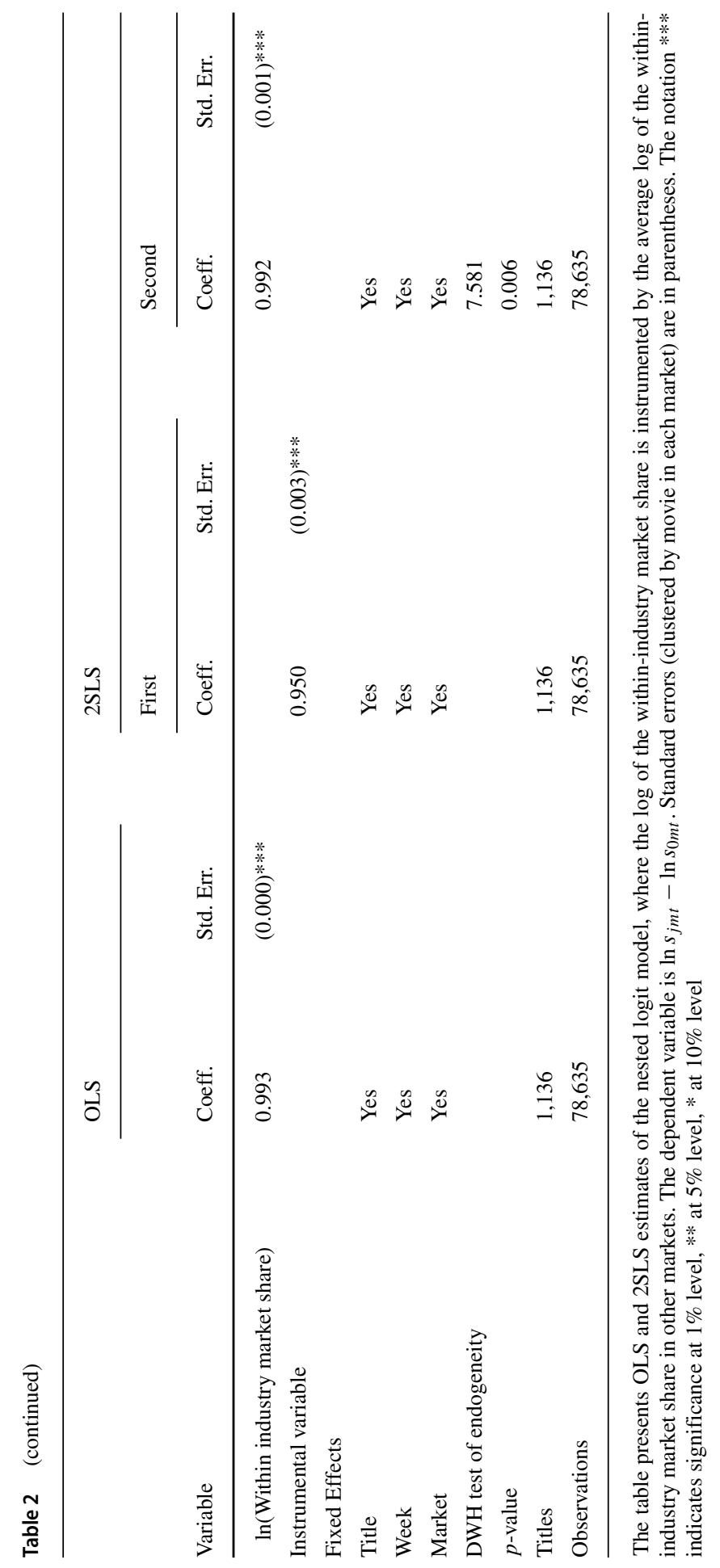


the sign is positive for all provinces except Kyungki, which surrounds Seoul - the largest city in Korea - and is part of the Seoul Metropolitan Area.

Indeed, the left panel of Fig. 6 in the Appendix illustrates that the negative effect of COVID-19 in a market, that is, the sum of the COVID-19 coefficient and the interaction term coefficient, tends to increase with population density. ${ }^{25} \mathrm{I}$ also examine the relationship between the number of screens per 1,000 people and the size of the COVID-19 effect; consumers in a market with higher per capita screen count go to the movie theater more often (assuming that the observed screen count is the equilibrium screen count), and the COVID-19 effect may be larger in the market. This conjecture is partially supported by the scatter plot in the right panel of Fig. 6 in the Appendix. ${ }^{26}$ Consequently, while the pandemic effect may depend on various market characteristics, population density seems to be one of the critical factors; people in metropolitan areas practiced social distancing more carefully than people in areas with lower population density including Kyungbook and Kyungnam, the two provinces surrounding Daegu. Given that the total number of infections began to surge only in the fourth week of February (Panel (a) of Fig. 1), the negative impact of COVID-19 on movie demand in these two provinces would have been larger than that in the table, had observations of the last week of February and later been used in the analysis. $^{27}$

Results in Table 2 also shows that the estimated value of $\sigma(0.992)$ is much larger than the estimated value using the U.S. data (0.52 in Einav (2007) and 0.37 in Leung et al. 2019), suggesting that in Korea movies take consumers mostly from each other rather than attracting those who do not go to the cinema. Additionally, the market share of a movie decreases over time, while box-office revenue jumps during holidays. Figure 5 compares the distribution of the estimated movie fixed effects for (i) movies released during the pandemic period (4th-8th week) in 2020 and (ii) movies released during the same period in the previous years (2017-2019). The figure shows that as expected the quality tends to be much lower for movies in the first group compared to movies in the second group.

Figure 7 in the Appendix presents the observed and predicted industry market shares, and reveals that the model replicates the observed industry market shares quite well in all markets. ${ }^{28}$ Accordingly, the relative difference between the predicted and the observed revenues presented in Table 7 in the Appendix is quite small (3.3 - 9.2 percent) in all markets.

\subsection{Revenue loss}

Using the estimated parameters of model (4), I examine what box-office revenue would have been in each market and nationwide during the first five weeks after the

\footnotetext{
${ }^{25}$ The correlation coefficient is -0.51 .

${ }^{26}$ The correlation coefficient is -0.22 .

${ }^{27}$ The sample period ends at the third week of February.

${ }^{28}$ Predicted industry market share in a week is the sum of the predicted market shares of all available movies in that week, averaged over the years.
} 


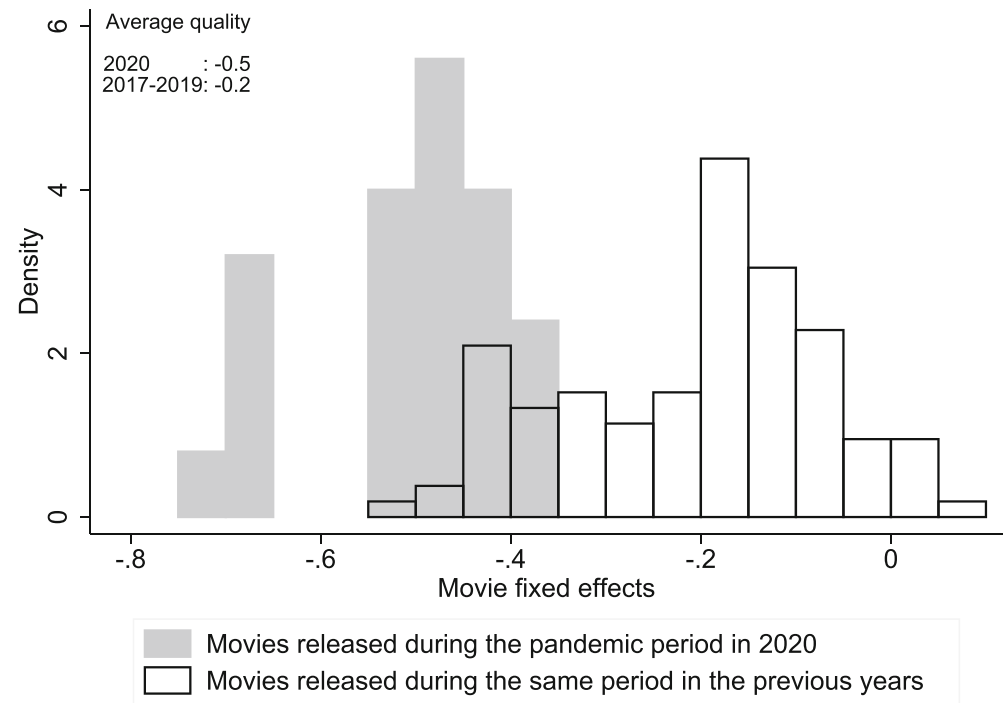

Fig. 5 Distribution of the movie fixed effects The figure compares the distribution of the estimated movie fixed effects for (i) movies released during the pandemic period (4th-8th week) in 2020 and (ii) movies released during the same period in the previous years (2017-2019)

outbreak of COVID-19 had it not broken out. The counterfactual industry market share in market $m$ at time $t$ is:

$$
s_{m t}^{*}=\frac{\left(\sum_{f=1}^{\mathcal{F}_{m t}} \exp \left(\hat{\delta}_{f m t}^{*} /(1-\hat{\sigma})\right)\right)^{1-\hat{\sigma}}}{1+\left(\sum_{f=1}^{\mathcal{F}_{m t}} \exp \left(\hat{\delta}_{f m t}^{*} /(1-\hat{\sigma})\right)\right)^{1-\hat{\sigma}}},
$$

where $\hat{\delta}_{f m t}^{*}$ is the predicted mean utility of the movie with the value of $C O V I D-19$ equal to zero instead of one. For each market and week, I get the difference between the counterfactual and observed industry market shares, $s_{m t}^{*}$ and $s_{m t}$. Then, the shortrun revenue loss owing to the social distancing practices in market $m, R L_{m}$, is

$$
R L_{m}=\sum_{t=0}^{4} p_{m t}\left(s_{m t}^{*}-s_{m t}\right) \cdot M S_{m},
$$

where $p_{m t}$ is the average admission price in market $m$ at week $t$, which is obtained by dividing the observed box-office revenue by the observed audience size, and $M S_{m}$ is the market size.

Table 3 presents estimated short-run revenue loss for each market as well as the 95 percent confidence intervals that are based on 200 cluster bootstrap replications. It ranges from 400 thousand dollars (in Jeju) to 16 million dollars (in Seoul). I also divide the lost revenue by the number of theaters in each market to derive the revenue 
Table 3 Revenue loss

\begin{tabular}{lllllll}
\hline & \multirow{2}{*}{ Estimated } & \multicolumn{2}{l}{$95 \%$ Confidence interval } & & Number of & \multirow{2}{*}{ Revenue loss } \\
Market & revenue loss & Lower bound & Upper bound & & theaters & per theater \\
\hline Busan & 4,111 & 3,619 & 4,602 & 29 & 142 \\
Choongbook & 1,339 & 1,083 & 1,596 & 19 & 70 \\
Choongnam & 1,582 & 1,246 & 1,918 & 25 & 63 \\
Daegu & 2,818 & 2,532 & 3,104 & 25 & 113 \\
Daejeon & 1,546 & 1,301 & 1,791 & 14 & 110 \\
Gwangju & 1,721 & 1,462 & 1,979 & 17 & 101 \\
Incheon & 2,671 & 2,238 & 3,104 & 27 & 99 \\
Jeju & 397 & 326 & 468 & 6 & 66 \\
Jeonam & 403 & 286 & 520 & 21 & 19 \\
Jeonbook & 1,076 & 873 & 1,279 & 27 & 40 \\
Kangwon & 1,068 & 865 & 1,272 & 26 & 41 \\
Kyungbook & 1,249 & 1,020 & 1,477 & 30 & 42 \\
Kyungki & 12,789 & 11,497 & 14,081 & 115 & 111 \\
Kyungnam & 2,100 & 1,773 & 2,428 & 32 & 66 \\
Seoul & 16,491 & 14,616 & 18,365 & 90 & 183 \\
Ulsan & 872 & 709 & 1,035 & 8 & 109 \\
Total & 52,253 & & & 511 & \\
\hline
\end{tabular}

Table 3 presents estimated short-run revenue loss (in 1,000 US dollars) for each market as well as the 95 percent confidence intervals that are based on 200 cluster bootstrap replications. Two out of 513 theaters in Korea are located in Sejong, the city that is excluded from the analysis

loss per theater. ${ }^{29}$ According to the table, theaters in Seoul were hit the most severely with an average sales loss of $\$ 183,000$ due to reduced movie demand. The estimated revenue loss is 52 million dollars nationwide, while the observed box-office revenue during the five weeks is 102 million dollars, as can be seen in Table 6 in the Appendix. This implies that social distancing caused a sales drop of 34 percent in the industry during the first five weeks after the outbreak of COVID-19.

Note that the difference between sales during the five weeks in 2020 and the sales during the same period in the previous year, 94 million dollars, reported in Table 6 in the Appendix, is much larger than the estimated nationwide revenue loss, 52 million dollars. This discrepancy can be largely attributed to endogenous movie quality choice by distributors. That is, as people were practicing social distancing and thus reluctant to go to the cinema, major distributors delayed some of their potentially popular movies. Table 8 in the Appendix, for example, shows that the number of newly released movies during the first two months is 30 percent lower in 2020 (40) than in the previous year (59), while movies released by the 10 largest distributors -

\footnotetext{
${ }^{29}$ There are 513 theaters in Korea as of December 2019. Two are located in Sejong, the city that is excluded from the analysis.
} 
five domestic distributors and five foreign distributors - decreased from 25 to $16 .{ }^{30}$ This suggests that the overall quality of available movies in the market might have decreased significantly. Indeed, the estimated quality tends to be much lower for movies released during the pandemic period (4th-8th week) in 2020 compared to movies released during the same period in the previous years (2017-2019), as can be seen in Fig. 5.

\section{Robustness}

\subsection{Alternative identification strategy}

Here, I consider two alternative identification strategies. First, since consumers in metropolitan cities (provinces) may have similar movie tastes, the error term may be correlated across cities (provinces). I address this concern by using the average log of the within-industry market share of the movie among provinces as the instrumental variable if the focal market is a metropolitan city. Similarly, I use the average log of the within-industry market share of the movie among metropolitan cities as the instrumental variable if the focal market is a province. ${ }^{31}$ This identification strategy allows the error term to be correlated across metropolitan cities and across provinces, but not between any metropolitan city and province. Estimates of the movie demand model and the estimated revenue loss reported in the first two columns of Tables 9 and 11 in the Appendix are similar to the estimation results from the main identification strategy in the previous section.

Second, similar to Einav (2007), I count the number of major movies - movies released by the 10 largest distributors - playing in a given market and week, and use it as the instrumental variable for the within-industry market shares. The identifying assumption is that while the number of major movies negatively affects the withinindustry share of a movie, it is not correlated with the movie-market-time specific variation in utility, $\xi_{j m t}$. Hence, the assumption would be violated if a movie that gets a strong random demand shock in a market induces the major distributors to adjust their screening schedules in the market. Estimates in the third and fourth columns of Table 9 in the Appendix are quite different from those in Table 2. For instance, the estimated value of $\sigma$ (0.644) suggest a stronger market-expansion effect from an additional movie. Also, the negative impact of the COVID-19 outbreak on consumer utility is more than twice as large as that in Table 2, and accordingly the estimated revenue loss reported in Table 11 in the Appendix (75 million dollars) is 40 percent larger than the estimated loss in Table 3 (52 million dollars). Since the audience size trend shown in Panel (a) of Fig. 2 suggests that there may not be much market expansion effect in the Korean movie theater industry, I keep the main estimation

\footnotetext{
${ }^{30}$ According to Korean Film Council Annual Report 2019, the combined market share of these 10 distributors was 88 percent in 2019 in terms of box-office revenue.

${ }^{31}$ Since Kyungki province's population density is much higher than the population density in other provinces (Table 5 in the Appendix) and it is part of the Seoul Metropolitan Area, I treat it as a metropolitan city here.
} 
strategy - that is, using average within-industry market share in other markets as the instrumental variable - unchanged.

\subsection{Time-varying effect of the COVID-19 pandemic}

In the previous section, $C O V I D-19_{t}$ is interacted with the market dummies, allowing the level of social distancing to differ across markets. It may also vary over time depending on how concerned people are about the novel coronavirus or how much information on the virus is available. To check whether this argument is supported by the data, I use Search se $_{\text {, }}$, theogle search volume related to the virus in market $m$ in week $t$, as the proxy for the degree of concern or amount of information on the

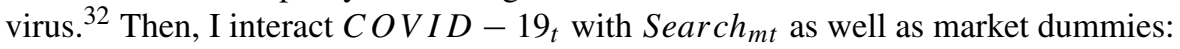

$$
\left(\psi_{m}+\tau \text { Search }_{m t}\right) \text { COVID }-19_{t} .
$$

Estimates in the fifth and sixth columns of Table 9 in the Appendix reveal that the larger the search volume, the lower the consumer's utility. This finding suggests that, consistent with the above conjecture, people are more afraid of going to the cinema when they are more concerned about the pandemic or there is more news about the novel virus. As for the revenue loss, the fifth and sixth columns of Table 11 in the Appendix show that consideration of the dynamics of information flow hardly affects the revenue loss estimation.

I further check the robustness of the empirical findings by including more timevarying controls. More specifically, I interact COVID $-19_{t}$ with the number of weeks passed and with a holiday dummy. ${ }^{33}$ This allows the decay rate and holiday effect to differ before and after the pandemic, which would prevent error term $\xi_{j m t}$ from being correlated across markets if the decay rate actually changed after the outbreak.

According to the estimation results reported in the last two columns of Table 9 in the Appendix, consumer utility from watching a movie decays faster after the COVID-19 outbreak, while the holiday effect tends to be larger than before the outbreak. Estimated revenue loss reported in the last two columns of Table 11 in the Appendix (47 million dollars) is a bit smaller than that reported in the previous section (52 million dollars).

\subsection{Additional robustness checks}

As the last step, I conduct two additional robustness checks. First, I add a quadratic term $r_{j t}^{2}$ in the utility specification (1), allowing for non-linear decay in utility.

\footnotetext{
${ }^{32}$ Consistent with Panel (b) of Fig. 1, I use the search volume for the three terms related to the virus -'Wuhan pneumonia', 'Novel coronavirus', 'Corona 19'.

${ }^{33}$ I also consider interacting $C O V I D-19 t$ with the $\log$ of the within-industry market share, and using the interaction between $C O V I D-19_{t}$ and the original instrumental variable as an additional instrument. Under this specification, however, the estimated value of $\sigma$ (1.02) exceeds its maximum value 1 after the pandemic, and the difference is statistically significant. Hence, I maintain the assumption that $\sigma$ is constant across time.
} 
Second, I replace the threshold value of the nationwide number of screens from 50 to 30 and 70 . That is, I drop movies that were played in fewer than 30 and 70 screens nationwide at all weeks during their run. Estimation results of the demand model (4) reported in Table 10 in the Appendix show that the utility from watching a movie decays faster in the beginning of its theatrical run, while estimates of other parameters are not significantly affected by the changes in model specification and number of observations. Estimated revenue losses reported in Table 12 in the Appendix are also similar to those from the baseline case in Table 3 .

\section{Conclusions}

The COVID-19 outbreak has caused consumers to practice social distancing and shift to online shopping. Although it is not surprising that brick-and-mortar retailers were severely hit by the reduced foot traffic, how much their sales dropped is an empirical question. In this paper, I study the short-run impact of the COVID-19 outbreak on the Korean movie theater industry through the change in consumer behavior, quantifying the revenue loss due to consumers' voluntary social distancing practices during the first five weeks after the outbreak.

Using movie-market-week level data between January 2017 and February 2020, I first estimate the discrete-choice model of movie demand. I find evidence that the COVID-19 outbreak had a strong negative impact on consumer utility in all markets in Korea. Additionally, results suggest that in Korea, movies are unlikely to expand the market by attracting those who do not go to the cinema. Next, using the estimated demand parameters, I examine what box office revenue would have been in each market and nationwide during the first five weeks after the outbreak of COVID-19 had it not broken out. Results reveal that the estimated short-run revenue loss owing to reduced underlying movie demand amounts to 52 million dollars nationwide.

In this paper, I focus on the short-run effect of the COVID-19 outbreak. As consumers are likely to switch to streaming services such as Netflix and Disney+, it would be interesting to examine how many of them would come back to theaters in the long run. Also, the severe revenue loss may change the competitive environment in the industry in the long run. If so, studying the effect of the change in market structure on consumer welfare would be another important research topic.

Acknowledgments I thank two anonymous referees and Thomas Otter, the Editor, for excellent comments and suggestions that helped to improve this paper. Financial support from the Seed Program for Korean Studies through the Ministry of Education of the Republic of Korea (AKS-2018-INC-2230011) and the Small Grant Program at Nazarbayev University (SHSS2018004) is gratefully acknowledged.

\section{Compliance with Ethical Standards}

Conflict of interests The author declares that he has no conflict of interest. 


\section{Appendix}

Table 4 Distribution and exhibition in 2019

Source: Korean Film Council Annual Report 2019

Table 5 Population size and density in 2018

Population size is in millions and population density is per sq. km. Source: Korean Statistical Information Service

\begin{tabular}{|c|c|c|c|c|}
\hline \multirow[b]{2}{*}{ Type } & \multicolumn{2}{|c|}{ Distribution } & \multicolumn{2}{|c|}{ Exhibition } \\
\hline & Movies & $\begin{array}{l}\text { Audience } \\
\text { (in millions) }\end{array}$ & Theaters & Screens \\
\hline \multicolumn{5}{|l|}{ Integrated firms } \\
\hline CJ & 19 & 53 & 168 & 1,221 \\
\hline Lotte & 15 & 16 & 130 & 915 \\
\hline JContentree & 6 & 2 & 102 & 699 \\
\hline Non-integrated theaters & & & 113 & 244 \\
\hline \multicolumn{5}{|c|}{ Non-integrated distributors } \\
\hline Foreign distributors & 1,247 & 111 & & \\
\hline Other domestic distributors & 657 & 45 & & \\
\hline Total & 1,944 & 227 & 513 & 3,079 \\
\hline
\end{tabular}

\begin{tabular}{|c|c|c|c|c|c|}
\hline \multirow[b]{2}{*}{ Market } & \multicolumn{2}{|c|}{ Population } & \multicolumn{2}{|c|}{ Korean citizen only } & \multirow{2}{*}{$\begin{array}{l}\text { Population } \\
\text { density }\end{array}$} \\
\hline & All age & $10-80$ & All age & $10-80$ & \\
\hline \multicolumn{6}{|c|}{ Metropolitan city } \\
\hline Busan & 3.40 & 3.08 & 3.34 & 3.03 & 4,507 \\
\hline Daegu & 2.44 & 2.20 & 2.41 & 2.17 & 2,801 \\
\hline Daejeon & 1.51 & 1.36 & 1.49 & 1.34 & 2,784 \\
\hline Gwangju & 1.49 & 1.33 & 1.46 & 1.31 & 2,921 \\
\hline Incheon & 2.94 & 2.64 & 2.85 & 2.55 & 2,774 \\
\hline Seoul & 9.67 & 8.84 & 9.30 & 8.48 & 16,287 \\
\hline Ulsan & 1.15 & 1.03 & 1.12 & 1.00 & 1,098 \\
\hline \multicolumn{6}{|l|}{ Province } \\
\hline Choongbook & 1.62 & 1.45 & 1.57 & 1.39 & 215 \\
\hline Choongnam & 2.18 & 1.93 & 2.09 & 1.84 & 257 \\
\hline Jeju & 0.66 & 0.58 & 0.63 & 0.56 & 355 \\
\hline Jeonam & 1.79 & 1.58 & 1.75 & 1.54 & 154 \\
\hline Jeonbook & 1.82 & 1.62 & 1.78 & 1.58 & 230 \\
\hline Kangwon & 1.52 & 1.37 & 1.50 & 1.34 & 92 \\
\hline Kyungbook & 2.67 & 2.39 & 2.60 & 2.31 & 141 \\
\hline Kyungki & 13.10 & 11.70 & 12.54 & 11.16 & 1,264 \\
\hline Kyungnam & 3.35 & 2.98 & 3.25 & 2.89 & 321 \\
\hline
\end{tabular}


Table 6 Box-office revenue comparison

\begin{tabular}{|c|c|c|c|c|}
\hline \multirow{3}{*}{$\begin{array}{l}\text { Table } 6 \text { Box-office revenue } \\
\text { comparison }\end{array}$} & \\
\hline & \multirow[b]{2}{*}{ Market } & \multicolumn{2}{|c|}{ Revenue (4th-8th weeks) } & \multirow[t]{2}{*}{ Difference } \\
\hline & & 2019 & 2020 & \\
\hline & Busan & 13,836 & 7,358 & 6,479 \\
\hline & Choongbook & 5,358 & 2,782 & 2,577 \\
\hline & Choongnam & 6,271 & 3,287 & 2,985 \\
\hline & Daegu & 10,419 & 5,249 & 5,171 \\
\hline & Daejeon & 6,797 & 3,712 & 3,085 \\
\hline & Gwangju & 6,939 & 3,703 & 3,236 \\
\hline & Incheon & 10,498 & 5,165 & 5,333 \\
\hline & Jeju & 2,073 & 1,189 & 885 \\
\hline & Jeonam & 4,469 & 2,467 & 2,002 \\
\hline & Jeonbook & 5,925 & 3,222 & 2,703 \\
\hline & Kangwon & 4,878 & 2,492 & 2,385 \\
\hline \multirow{6}{*}{$\begin{array}{l}\text { The table compares sales during } \\
\text { the first five weeks after the } \\
\text { COVID- } 19 \text { outbreak in } 2020 \\
\text { ( } 4 \text { th- } 8 \text { th week of the year) and } \\
\text { the sales during the same period } \\
\text { in the previous year. Revenues } \\
\text { are in } 1,000 \text { US dollars. Source: } \\
\text { KOBIS }\end{array}$} & Kyungbook & 6,544 & 3,325 & 3,218 \\
\hline & Kyungki & 48,929 & 24,238 & 24,691 \\
\hline & Kyungnam & 10,240 & 5,507 & 4,733 \\
\hline & Seoul & 48,803 & 26,535 & 22,268 \\
\hline & Ulsan & 4,327 & 2,301 & 2,026 \\
\hline & Total & 196,307 & 102,532 & 93,775 \\
\hline
\end{tabular}

Revenue (4th-8th weeks)

Difference 
Table 7 Predicted vs observed revenue

The table presents predicted and observed revenues for each market during the first five weeks after the COVID-19 outbreak in 2020 (4th-8th week of the year). Revenues are in 1,000 US dollars

Table 8 Number of new movies

Source: KOBIS

\begin{tabular}{|c|c|c|c|}
\hline \multirow[b]{2}{*}{ Market } & \multicolumn{2}{|c|}{ Revenue (4th-8th weeks) } & \multirow{2}{*}{$\begin{array}{l}\text { Relative } \\
\text { difference }(\%)\end{array}$} \\
\hline & Predicted & Observed & \\
\hline Busan & 7,998 & 7,358 & 8.3 \\
\hline Choongbook & 3,005 & 2,782 & 7.7 \\
\hline Choongnam & 3,553 & 3,287 & 7.8 \\
\hline Daegu & 5,439 & 5,249 & 3.6 \\
\hline Daejeon & 3,974 & 3,712 & 6.8 \\
\hline Gwangju & 3,919 & 3,703 & 5.7 \\
\hline Incheon & 5,479 & 5,165 & 5.9 \\
\hline Jeju & 1,269 & 1,189 & 6.6 \\
\hline Jeonam & 2,551 & 2,467 & 3.3 \\
\hline Jeonbook & 3,374 & 3,222 & 4.6 \\
\hline Kangwon & 2,733 & 2,492 & 9.2 \\
\hline Kyungbook & 3,441 & 3,325 & 3.4 \\
\hline Kyungki & 26,290 & 24,238 & 8.1 \\
\hline Kyungnam & 5,846 & 5,507 & 6.0 \\
\hline Seoul & 29,089 & 26,535 & 9.2 \\
\hline Ulsan & 2,482 & 2,301 & 7.6 \\
\hline Total & 110,442 & 102,532 & 7.4 \\
\hline
\end{tabular}

\begin{tabular}{|c|c|c|c|c|}
\hline & \multirow[b]{2}{*}{ Year } & \multirow[b]{2}{*}{ Month } & \multicolumn{2}{|c|}{ Distributors } \\
\hline & & & All & Major \\
\hline & 2019 & 1 & 27 & $13 \mathrm{t}]$ \\
\hline & 2019 & 2 & 32 & 12 \\
\hline & 2019 & 3 & 24 & 10 \\
\hline & 2019 & 4 & 25 & 10 \\
\hline & 2019 & 5 & 30 & 10 \\
\hline & 2019 & 6 & 21 & 9 \\
\hline & 2019 & 7 & 25 & 11 \\
\hline & 2019 & 8 & 27 & 9 \\
\hline & 2019 & 9 & 31 & 10 \\
\hline & 2019 & 10 & 38 & 10 \\
\hline & 2019 & 11 & 32 & 8 \\
\hline & 2019 & 12 & 27 & 11 \\
\hline & 2020 & 1 & 24 & 7 \\
\hline & 2020 & 2 & 16 & 9 \\
\hline
\end{tabular}




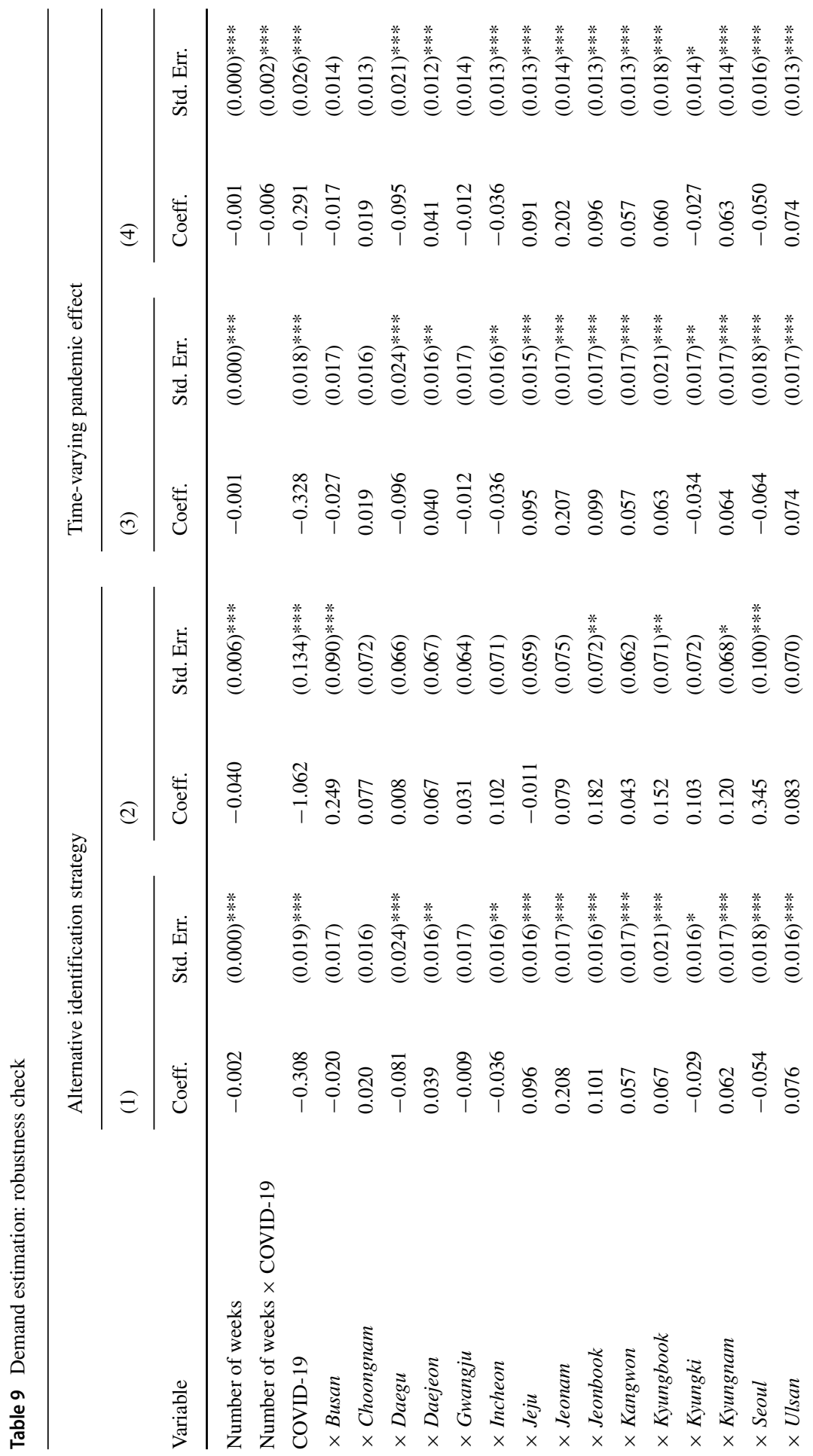




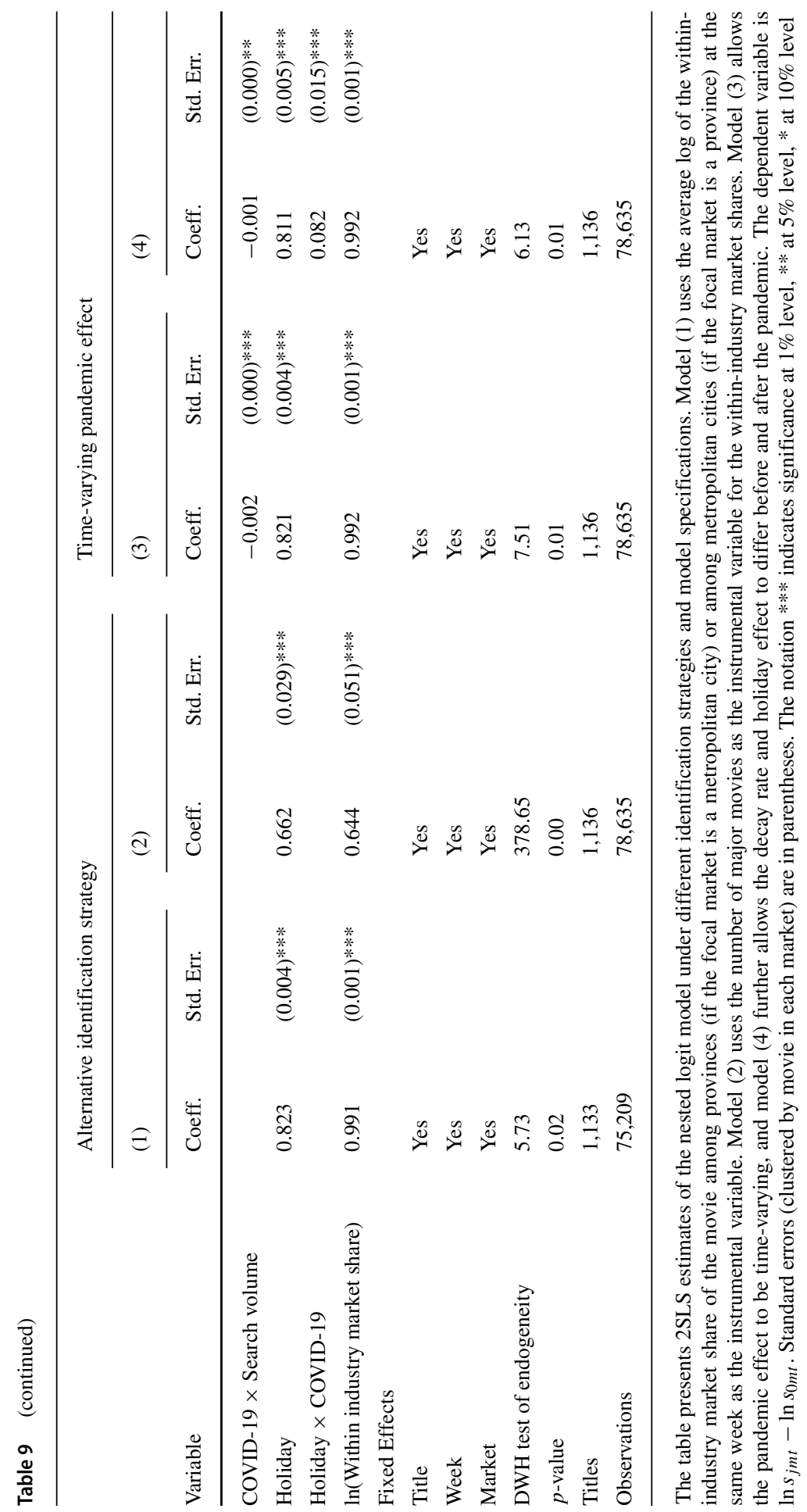




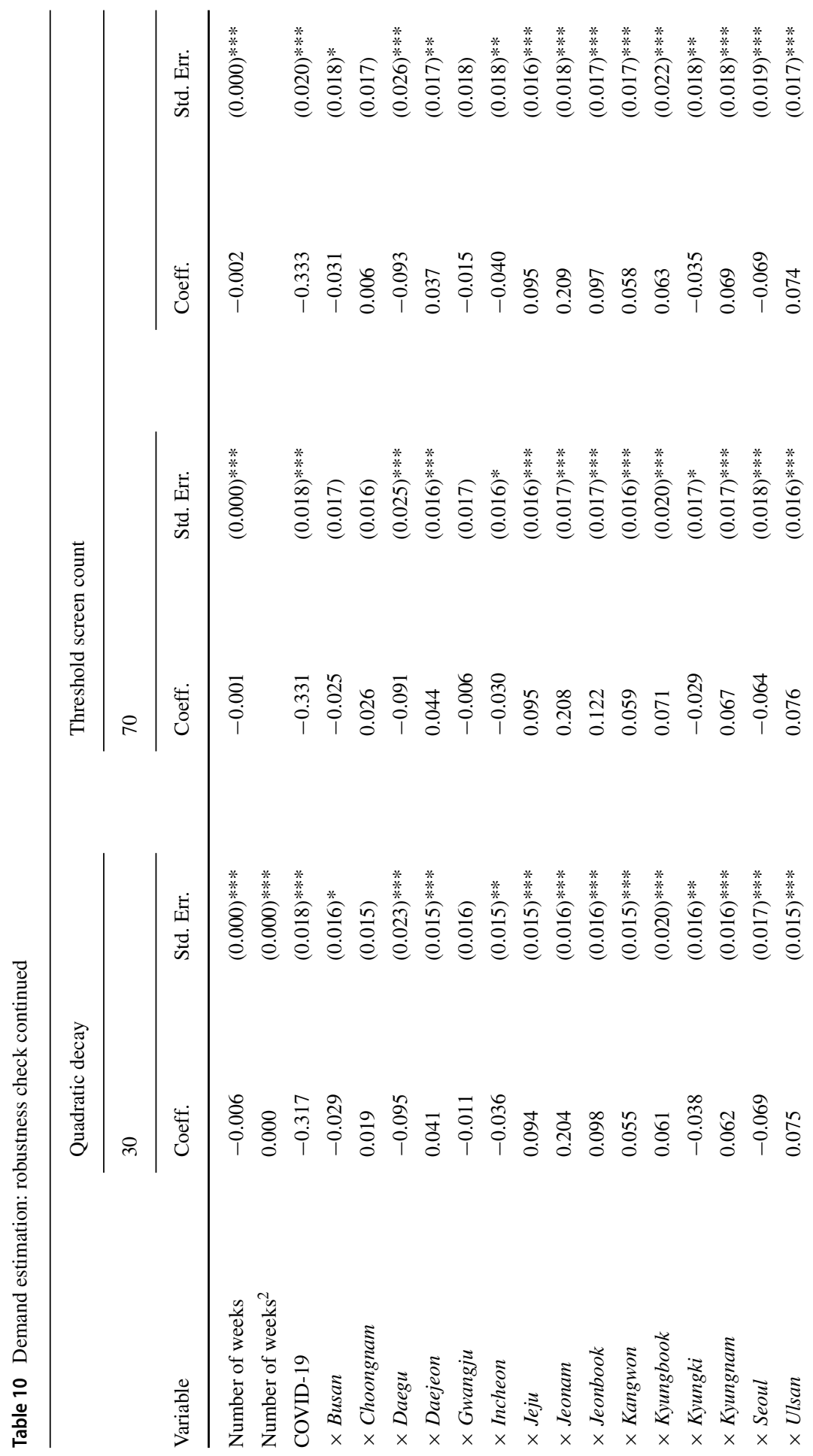




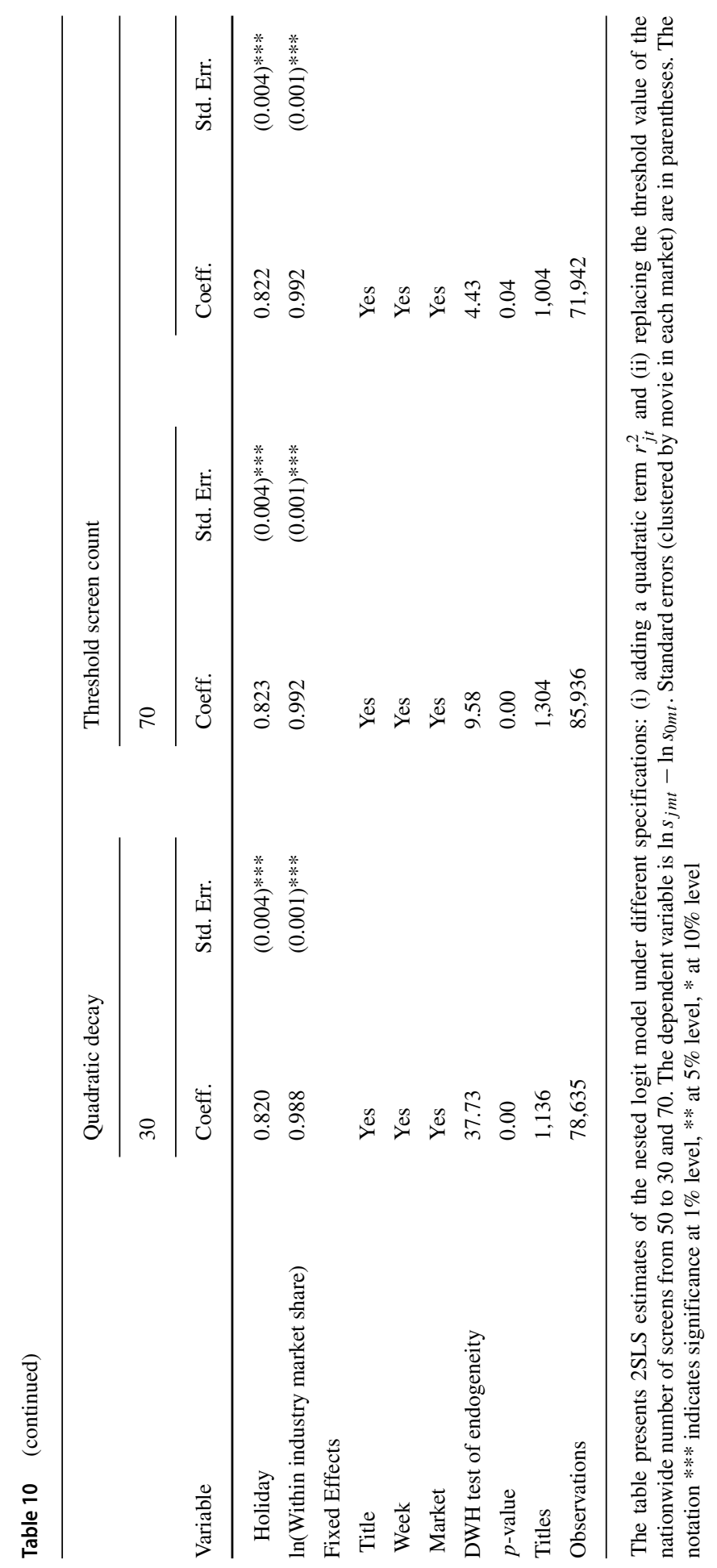




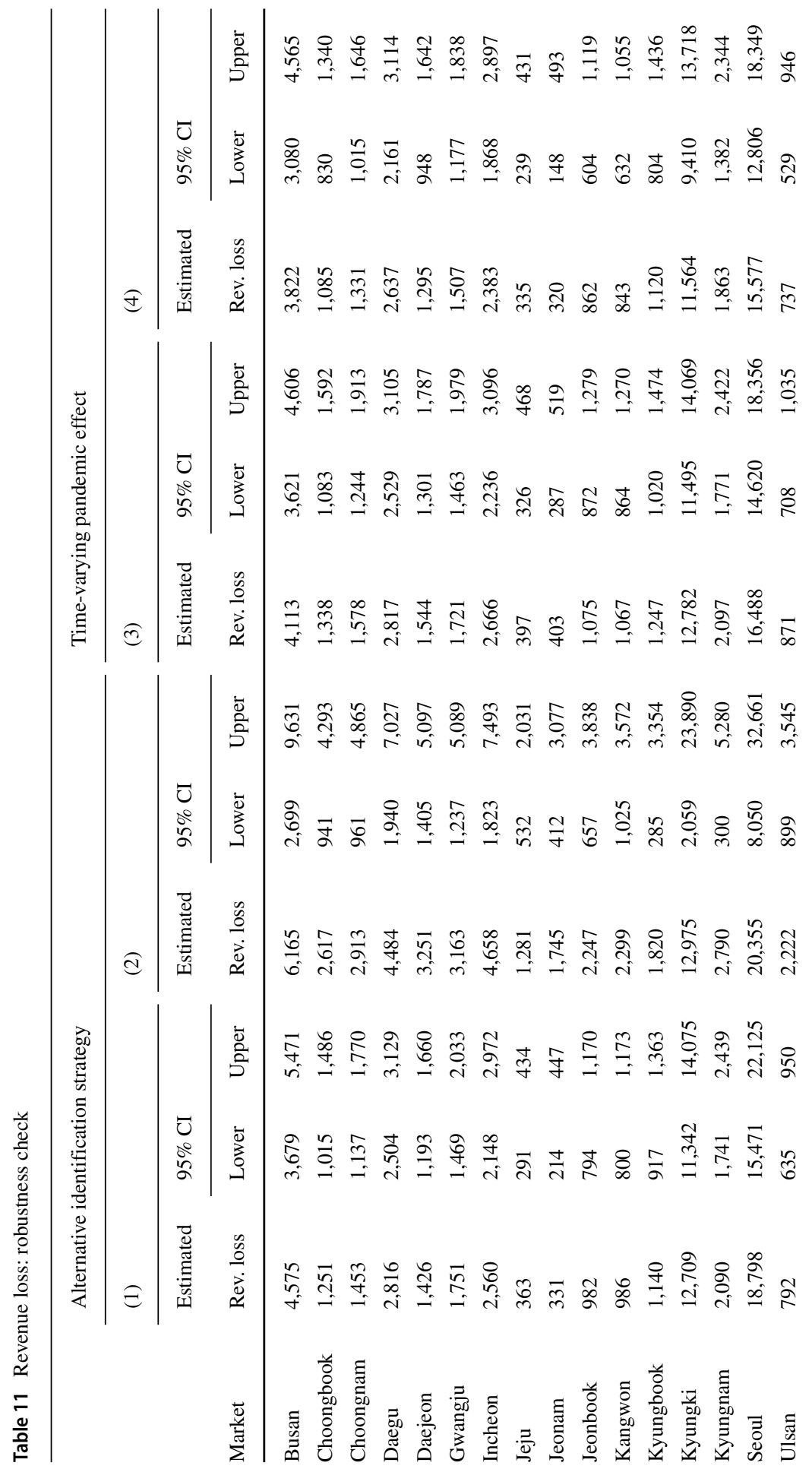




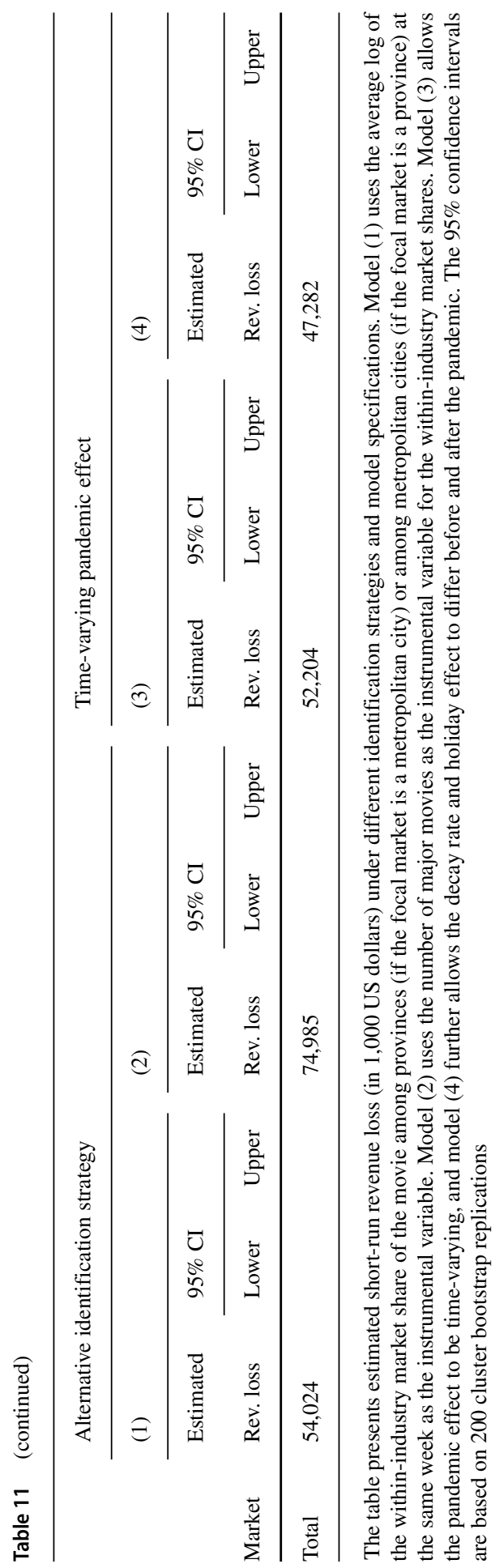




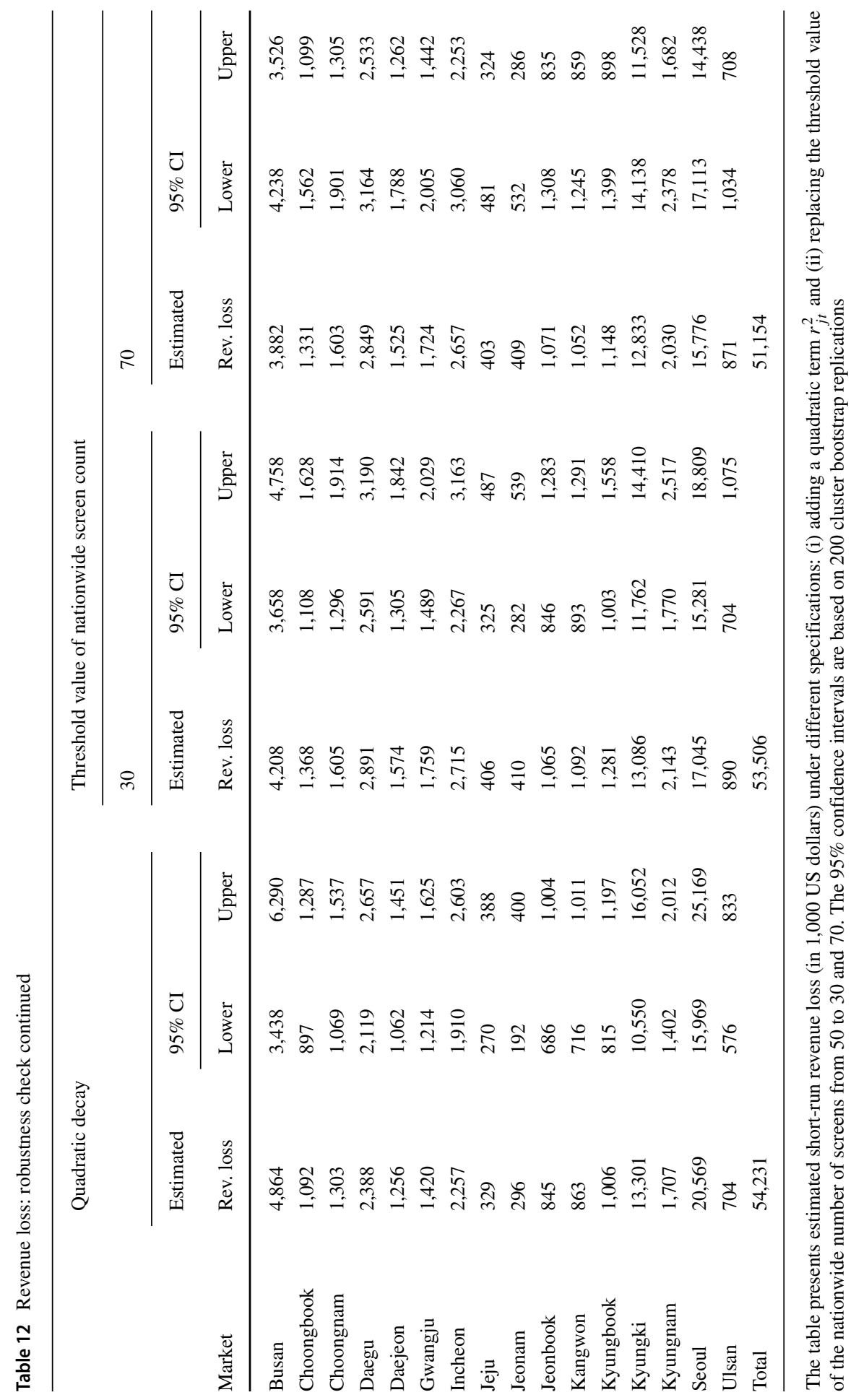


(a) Population density

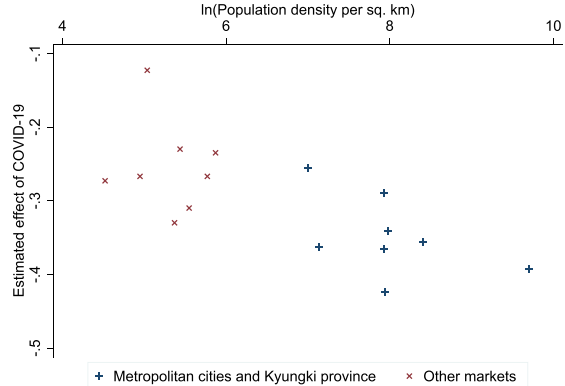

(b) Per capita screening capacity

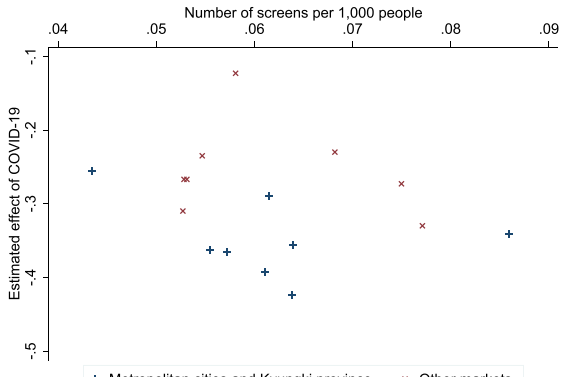

+ Metropolitan cities and Kyungki province $\quad \times$ Other markets

Fig. 6 Market characteristics and the size of the COVID-19 effect The figure shows the relationship between the log of the population density and the size of the COVID-19 effect (in the left panel) and between the number of screens per 1,000 people and the size of the COVID-19 effect (in the right panel) among the 16 markets analyzed in this paper

Busan

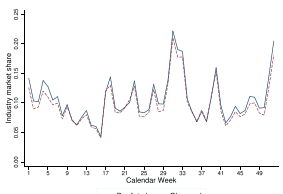

Daejeon

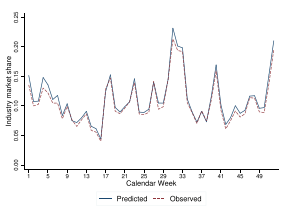

Jeonam

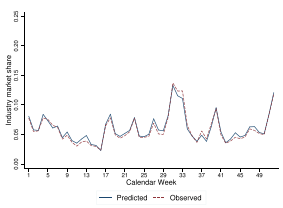

Kyungki

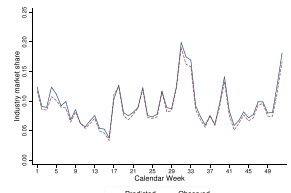

Choongbook

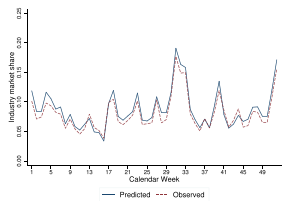

Gwangju

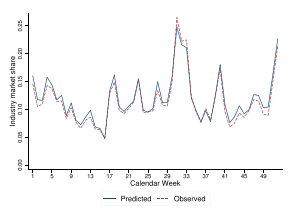

Jeonbook

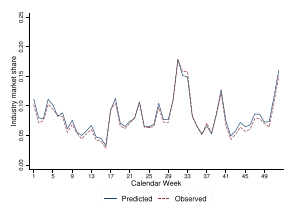

Kyungnam

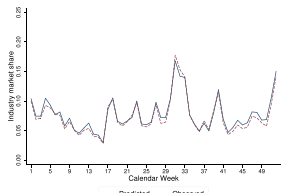

Choongnam

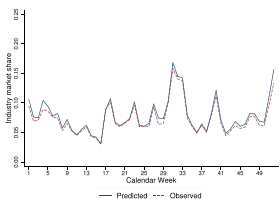

Incheon

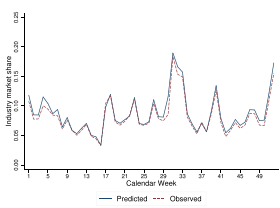

Kangwon

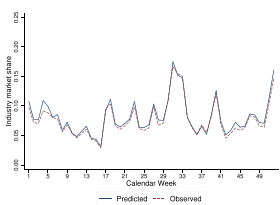

Seoul

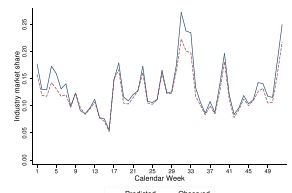

Daegu

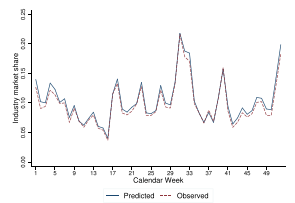

Jeju

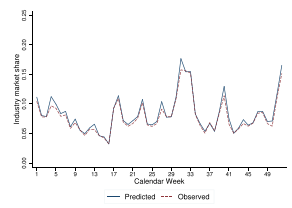

Kyungbook

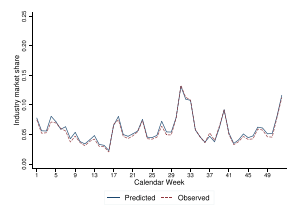

Ulsan

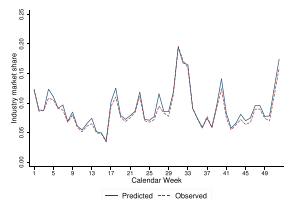

Fig.7 Demand model fit Each panel of the figure shows the observed and predicted industry market shares in each of the 16 markets. Predicted industry market share in a week is the sum of the predicted market shares of all available movies in that week, averaged over the years 


\section{References}

Adda, J. (2016). Economic activity and the spread of viral diseases: Evidence from high frequency data. The Quarterly Journal of Economics, 131(2), 891-941.

Alvarez, F., Argente, D., Lippi, F. (2020). A simple planning problem for covid-19 lockdown. Technical report, Discussion paper, EIEF.

Berry, S. (1994). Estimating discrete-choice models of product differention. RAND Journal of Economics, 25(2), 242-262.

Boucekkine, R., \& Laffargue, J.-P. (2010). On the distributional consequences of epidemics. Journal of Economic Dynamics and Control, 34(2), 231-245.

Cardell, S.N. (1997). Variance components structures for the extreme-value and logistic distributions with application to models of heterogeneity. Econometric Theory, 13(2), 185-213.

Chakraborty, S., Papageorgiou, C., Sebastián, F.P. (2010). Diseases, infection dynamics, and development. Journal of Monetary Economics, 57(7), 859-872.

Chen, M.-H., Jang, S.S., Kim, W.G. (2007). The impact of the sars outbreak on taiwanese hotel stock performance: an event-study approach. International Journal of Hospitality Management, 26(1), 200212.

Chiou, L., \& Tucker, C. (2020). Social distancing, internet access and inequality. Technical report, National Bureau of Economic Research.

Courty, P., \& Nasiry, J. (2018). Loss aversion and the uniform pricing puzzle for media and entertainment products. Economic Theory, 66(1), 105-140.

Durante, R., Guiso, L., Gulino, G. (2020). Civic capital and social distancing: evidence from italians' response to covid-19. VoxEU Column.

Eichenbaum, M.S., Rebelo, S., Trabandt, M. (2020). The macroeconomics of epidemics. Technical report, National Bureau of Economic Research.

Einav, L. (2007). Seasonality in the U.S. motion picture industry. RAND Journal of Economics, 38(1), 127-145.

Faria-e Castro, M., et al. (2020). Fiscal policy during a pandemic. Technical report.

Frutos, R., Roig, M.L., Serra-Cobo, J., Devaux, C.A. (2020). Covid-19: The conjunction of events leading to the coronavirus pandemic and lessons to learn for future threats. Frontiers in Medicine, 7, 223.

Guerrieri, V., Lorenzoni, G., Straub, L., Werning, I. (2020). Macroeconomic implications of covid-19: Can negative supply shocks cause demand shortages? Working Paper 26918, National Bureau of Economic Research.

Gupta, S., Simon, K., Wing, C. (2020). Mandated and voluntary social distancing during the covid-19 epidemic. BPEA Conference Draft, Summer.

Hausman, J. (1996). Valuation of new goods under perfect and imperfect competition. In The Economics of New Goods (pp. 207-248): National Bureau of Economic Research, Inc.

Jones, P.T., \& Venkateswaran, C.V. (2020). Optimal mitigation policies in a pandemic. Technical report, NYU.

Keogh-Brown, M.R., Smith, R.D., Edmunds, J.W., Beutels, P. (2010). The macroeconomic impact of pandemic influenza: estimates from models of the united kingdom, france, Belgium and the netherlands. The European Journal of Health Economics, 11(6), 543-554.

Kim, I.K. (2019). Organizational form and performance: the cinema chain case. Available at SSRN 3424510 .

Kim, I.K. (2020). Movie variety and the city. The BE Journal of Economic Analysis \& Policy, 20(3).

Kuo, H.-I., Chang, C.-L., Huang, B.-W., Chen, C.-C., McAleer, M. (2009). Estimating the impact of avian flu on international tourism demand using panel data. Tourism Economics, 15(3), 501-511.

Leung, T.C., Qi, S., Yuan, J. (2019). Movie industry demand and theater availability. Review of Industrial Organization, 1-25.

Maloney, W., \& Taskin, T. (2020). Determinants of social distancing and economic activity during covid19: A global view.

Moul, C.C. (2007). Measuring word of mouth's impact on theatrical movie admissions. Journal of Economics \& Management Strategy, 16(4), 859-892.

Moul, C.C. (2008). Retailer entry conditions and wholesales conduct: the theatrical distribution of motion pictures. International Journal of Industrial Organization, 26(4), 966-983.

Nevo, A. (2001). Measuring market power in the ready-to-eat cereal industry. Econometrica, 69(2), 307342 . 
Orbach, B.Y., \& Einav, L. (2007). Uniform prices for differentiated goods: the case of the movie-theater industry. International Review of Law and Economics, 27(2), 129-153.

Perrings, C., Castillo-Chavez, C., Chowell, G., Daszak, P., Fenichel, E.P., Finnoff, D., Horan, R.D., Kilpatrick, A.M., Kinzig, A.P., Kuminoff, N.V., et al. (2014). Merging economics and epidemiology to improve the prediction and management of infectious disease. EcoHealth, 11(4), 464-475.

Philipson, T. (2000). Economic epidemiology and infectious diseases. Handbook of Health Economics, 1 , 1761-1799.

Publisher's note Springer Nature remains neutral with regard to jurisdictional claims in published maps and institutional affiliations. 